3. The tongue, having been freed from the adventitious tissue is divided in its long axis, down to the base. Fig. 7.

The upper portion is tucked into the pocket formed in the upper lid, and becomes a partial lining to the lid. The lower portion is similarly transplanted downward into the pocket made below,

\section{SUBLUXATION OF EYEBALL.}

Paul S. Mertins, M.D., F.A.C.S. MONTGOMERY, ALA.

Rarity of the condition is reason for reporting this case. Henry Harold, (col.), aet. 38, shoemaker, called on account of a mild catarrhal conjunctivitis.

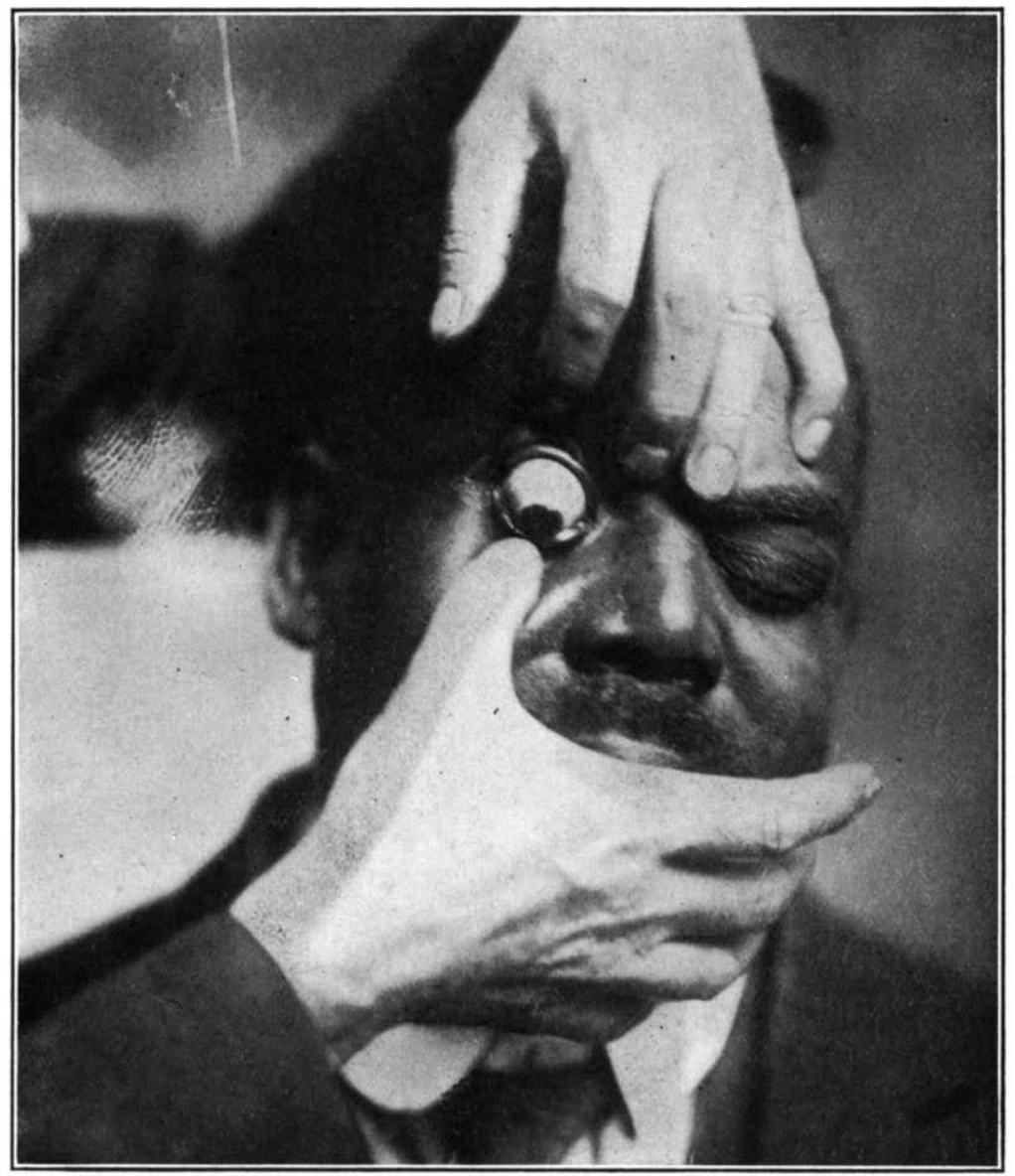

Fig. 1. Subluxation of right eye (Mertin's case).

covering a similar defect in the lining of the lower lid. Fig. 8.

4. The denuded bulbar surface is covered by conjunctival flaps in the manner described. Fig. 8.

The corneal site of the pterygium is curretted in the usual way, atropin instilled and some ointment like White's placed in the conjunctival sac. Both eyes are covered for a few days. The sutures may be removed after the fourth day.
He was six feet tall, well developed, well nourished, and of rather more than average racial intelligence. $\mathrm{He}$ had never had previous eye trouble, except snow glare conjunctivitis during the Spanish-American War. His general health was excellent and the shape of his head was good. There was nothing unusual about the expression of his eyes.

On retracting eyelids of right eye with 
fingers, to expose the conjunctiva, there was a rather rapid advance of the bulb, until it had passed the strait of the lids. So rapid was the advance that the bulb seemed to fairly pop out of the orbit. Holding the lids open with the fingers the subluxation was easily reduced by pressure on the bulb. There was some bleph- the bulb when the patient opened his eyes as wide as possible. Vision in each eye was $20 / 20$ with 0.50 cyl. ax. $90^{\circ}$. Fundus was normal. There was orthophoria. Examination of nose and accessory sinuses was negative.

The accompanying photographs illustrate, to a degree, the extent of subluxa-

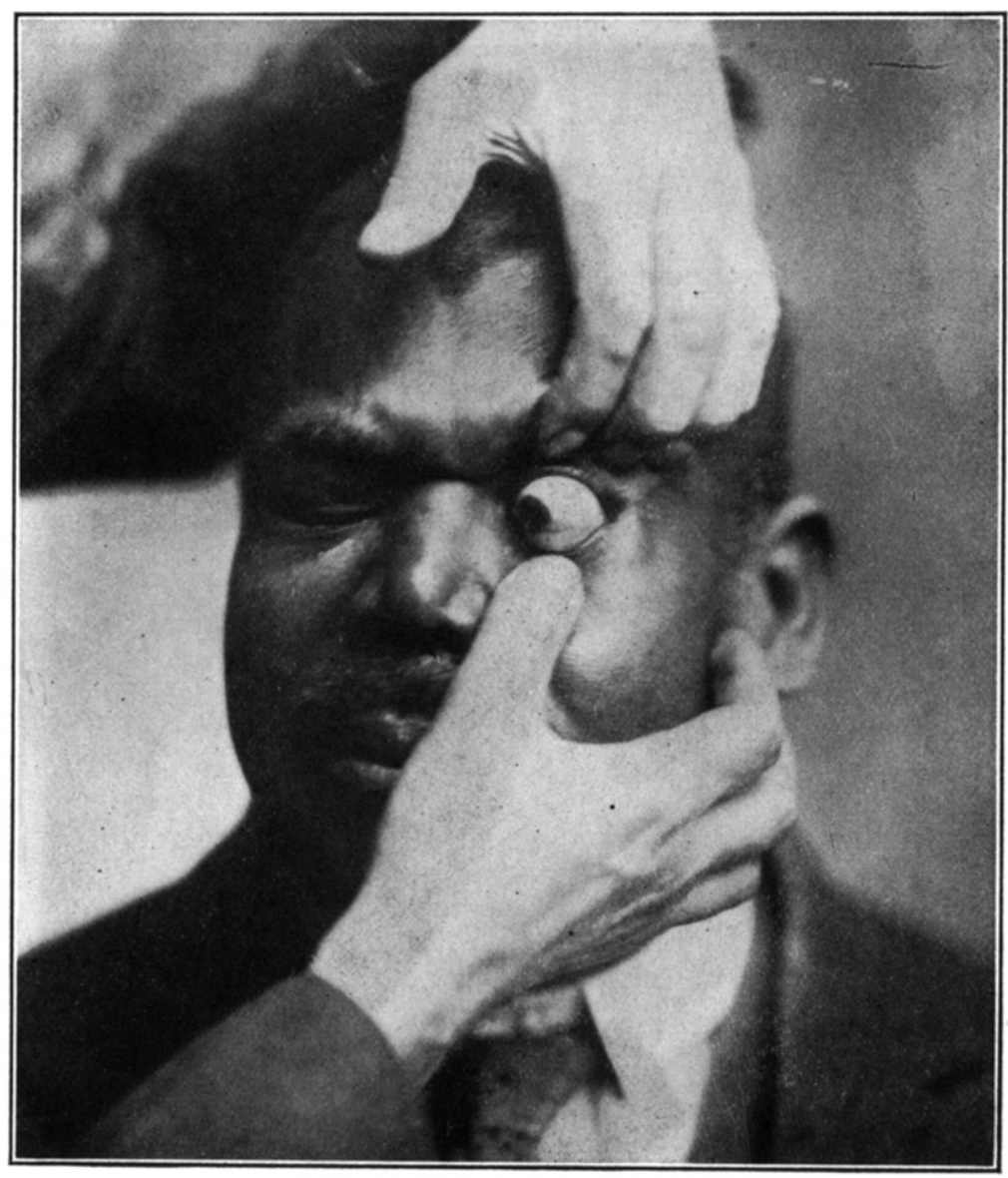

Fig. 2. Subluxation of left eye on retraction of lids.

arospasm and the patient complained of a slight ache in the eye for a few minutes.

Examination of left eye, in like manner, was followed by the same rapid advance of the bulb until it passed the lids.

There was no exophthalmos, tachycardia, tremor, or enlargement of thyroid gland.

Measuring from fixed point of the external bony edge of the orbit, there was noted an advance of six millimeters of tion. In making the photographs, care was taken not to let the bulb pass the strait of the lids, on account of the slight pain which was experienced. The photographs illustrate the normal appearance of each eye, as well as the subluxation of bulb, when the lids were retracted.

The patient gave no history of spontaneous luxation of the eye, and was not aware of the anomaly.

T. E. Oertel, (Amer. Jour. Ophth., Series 3, Vol. 3, No. 11), reports a case 
of spontaneous luxation of eyeball in a negress. His patient died suddenly, without known cause, and at autopsy, a small cerebellar tumor was found. Her first spontaneous luxation had occurred two months previously; no pathologic condition other than cercbellar tumor was noted.

Oertel reviews the literature from 1900 and finds reports of nine cases, besides his own. Two were insane, one had cerebral gumma, one had exophthalmic goitre, one bilateral exophthalmos without Basedow's disease, and in four cases no mention is made of any pathologic condition.

The suggestion of Levin, quoted by Oertel, of tarsorrhaphy in those cases of frequent spontaneotis occurrence seems practical.

\section{NEW KNIFE NEEDLE.}

$$
\text { J. F. Hileman, M.D., }
$$

$$
\text { SAN DIEGO, CALIF. }
$$

Having had considerable difficulty in getting satisfactory discission needles. I had some made from a special design, which are far superior to anything I have ever used before.

They are fine and delicate, with a special sickle shaped curve, needle point, double cutting edge, very thin blade with no shoulder at heel. The blade being only four millimeters from point to heel, gives great facility for movement in every direction when in the eye, with the advantage of a cutting edge on either side. On account of thinness of blade and lack of obstructing shoulder, its introduction into the eye is made with the greatest of ease and without the loss of aqueous during the manipulation. I am sure if my colleagues will try this needle they will be highly pleased with it.

F. A. Hardy \& Co. of Chicago made these needles for me in a superior workmanship manner.

\section{PRIMARY VACCINIA OF THE CORNEA.}

Noxon ToOMEy, M.D., SAINT LOUIS, MISSOURI.

The extensive destruction of the cornea and deeper tissues that follows upon the primary inoculation of vaccine $l y m p h$ into the cornea is so serious, that we believe it should be brought to the attention of the profession. The accidental vaccination of the cornea can often be prevented, if those who handle the virus are mindful of what may result frum carelessness. The modern method of marketing vaccine virus in capillary glass tubes favors the accidental inoculation of the cornea. The infecting wound is produced by a splinter of glass flying into an eye of the physician or bystander when one of the ends of the capillary tube is snapped off. That the tube of virus should be held so that flying splinters of glass will not strike an eye, is suggested by common prudence. Furthermore, we urge that no physician should consider himself immune from corneal vaccinia just because he had a successful vaccination a short time before. Even in well vaccinated persons, the virus when inoculated into the cornea is likely to give rise to a slight (anaphylactic) reaction sufficient to cause temporary distress or even slight permanent injury.

A case of vaccinia of the lids, recently seen with I)r. James Moores Ball, led the author to collect the literature on the subject of vaccinia of the ocular apparatus. The case reports in which the cornea was the seat of primary vaccinia are given below. Six of the eight cases were due to glass splinters from vaccine tubes. one to an ivory vaccine point, and one to a needle shot from a mechanical vaccinostyle.

The histopathology of experimental vaccinia of the cornea in animals is very fully discussed by the authors below:

\section{REFERENCES TO VACCINIA.}

Wasielewski. Zeit. f, Hygiene u. Inf.-Krankh., 38:212-318. 1901.

Critchett. Medical Examiner, December, 1876.

Eagleton. (Ophthaimic Record, N. S., 8:325. 1899.

Dochler. Berl. klin. Woch., 42:250. 1905.

Doehler. Lancet, $1: 999$. April 7, 1906.

Story: British Medical Jour., 1:346. 1907.

Menzies and Jamison Ihid, 1:198. 1907.

Cailland. Ia Clinique Ophtalmolog., Jan. 10, 1913. Ahst. in The Ophthalmoseope, $13: 150$.

Morax. Ann. d'Oculist., 152:345. Nov., 1914. Abst. in Ophthalmic Review, $35: 152-153$. 